\title{
Ultrasonographic examination of the reticulum, rumen, omasum, abomasum, and liver in calves
}

\author{
Braun, Ueli
}

\begin{abstract}
This article describes the ultrasonographic findings of the reticulum, rumen, omasum, abomasum, and liver of calves from birth to 100 days of age. Reticular motility is used to exemplify how the forestomach function in calves progresses and gradually approaches that of adult cattle. The ultrasonographic examination of the esophageal groove reflex and the investigation of factors affecting esophageal groove closure are described. The ultrasonographic findings of the forestomachs and abomasum of calves with ruminal drinker syndrome are discussed. The article concludes with the description of the ultrasonographic examination of the liver.
\end{abstract}

DOI: https://doi.org/10.1016/j.cvfa.2015.09.011

Posted at the Zurich Open Repository and Archive, University of Zurich ZORA URL: https://doi.org/10.5167/uzh-125643

Journal Article

Accepted Version

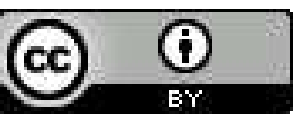

The following work is licensed under a Creative Commons: Attribution 4.0 International (CC BY 4.0) License.

Originally published at:

Braun, Ueli (2016). Ultrasonographic examination of the reticulum, rumen, omasum, abomasum, and liver in calves. The Veterinary clinics of North America. Food animal practice, 32(1):85-107.

DOI: https://doi.org/10.1016/j.cvfa.2015.09.011 


\section{Ultrasonographic examination of the reticulum, rumen, omasum, abomasum and liver}

in calves

Ueli Braun, Prof Dr med vet, Dr med vet h c

Ueli Braun, Prof Dr Med Vet, Professor for Internal Medicine of Cattle, Department of Farm

Animals, University of Zurich, Winterthurerstrasse 260, CH-8057 Zurich, Switzerland

E-mail address: ubraun@vetclinics.uzh.ch

Telephone number: 0041-44-6358241

Fax number: 0041-44-6358904

\section{Summary}

This article describes the ultrasonographic findings of the reticulum, rumen, omasum, abomasum and liver of calves from birth to 100 days of age. Changes in ultrasonographic appearance, location and size of these organs during the first 100 days are outlined. Reticular motility is used to exemplify how the forestomach function in calves progresses and gradually 
34 reflex and the investigation of factors affecting esophageal groove closure are described. The ultrasonographic findings of the forestomachs and abomasum of calves with ruminal drinker

36 syndrome are discussed. The article concludes with the description of the ultrasonographic 37 examination of the liver.

39 KEYWORDS

40 - Cattle $\cdot$ Calf $\bullet$ Ultrasonography $・$ Reticulum $・$ Rumen $・$ Abomasum $•$ Esophageal groove

41 reflex $\bullet$ Ruminal Drinker $\bullet$ Liver 


\section{Introduction}

Ultrasonographic findings of the reticulum, rumen, omasum and abomasum of mature cattle were recently summarized and published. ${ }^{1}$ The gastrointestinal tract of the calf undergoes significant changes associated with the development of the rumen and the transition from a milk-based to a roughage-based diet and differs from the tract of mature cattle. For this reason, ultrasonographic findings in mature cattle are not directly applicable to calves. In addition to ultrasonography, computed tomography is extremely useful for the assessment of the position, appearance and size of intra-abdominal organs and their changes during development of the calf. ${ }^{2-4}$ The aim of this review is to describe the abdominal organs in calves from birth to the age of 100 days. Calves used in ultrasonographic studies for the description of abdominal organs ranged in age from 0 to 14 days, ${ }^{5} 16$ to 33 days, ${ }^{6}$ and 87 to 90 days. ${ }^{6,8}$ To optimize the investigation of organ development in calves, a cohort of calves underwent serial ultrasonographic examination from birth to the age of 100 days. ${ }^{9-11}$ The goal of that study was to monitor and describe the development of the reticulum, rumen, omasum, abomasum, spleen, liver, gall bladder, caudal vena cava and portal vein in six healthy calves from birth to the age of 104 days.

\section{Technique of ultrasonographic examination of calves}

A 5.0 to $7.5-\mathrm{MHz}$ linear or convex transducer is ideal ${ }^{7,11}$ but a transducer with a higher resolution, for instance 13.0 MHz, may be used for the examination of organ walls. The investigation of the motility of the forestomachs and abomasum during the ingestion of milk is facilitated by video recording using a recorder connected to the ultrasound machine. This allows for the continuous recording of all images and in-depth analysis at a later date. The examinations are conducted in the standing non-sedated animal. To improve contact between transducer and skin, the hair is clipped, the skin cleaned with alcohol and obstetrical lubricant is applied to the skin. A contact gel is also applied to the transducer.

\section{Reticulum}

Examination of the reticulum

The reticulum is examined in the ventral median and left and right ventral thoracic regions with the transducer held parallel to the longitudinal axis of the calf, and the reticulum is identified. ${ }^{7,11}$ The contour and shape of the reticulum are assessed first and then the motility is recorded for $3 \mathrm{~min}$. The number and the amplitude of contractions are recorded. 


\section{Ultrasonographic findings of the reticulum}

The reticulum is rarely visualized in the first 2 weeks because it is very small and not close enough to the ventral abdominal wall to be within reach of the ultrasound beams. ${ }^{5,9,11}$ From the third week, the reticulum can always be visualized in the sternal region. The spleen or the liver is often seen between the ventral abdominal wall and the reticulum until the age of about 80 days (Fig. 1). After the age of 100 days, the reticulum is always adjacent to the ventral abdominal wall. The reticular wall appears as an echoic line as described in mature cattle. ${ }^{12}$ Because of its gaseous nature, the reticular content is not usually visible or it may appear as hypoechoic, cloudy, ill-defined material near the reticular wall. Small projections indicating the mucosal folds and the reticular honeycomb pattern are only seen in exceptional cases. Reticular contractions are biphasic similar to those seen in adult cattle. ${ }^{12}$ During rumination, contractions are triphasic as seen in adult cattle. The contraction preceding the normal biphasic contraction serves to transport the cud into the esophagus, from where it is propelled to the mouth and chewed. The frequency of reticular contractions increases significantly in the first 100 days of life; there were $0.9,1.0,1.2,1.4$ and 1.4 contractions per minute at the age of 20,40,60, 80 and 100 days, respectively. ${ }^{9,11}$

The reticulum cannot be visualized in pre-weaned calves during and $30 \mathrm{~min}$ after ingestion of milk because it is displaced craniodorsally by the expanding abomasum and becomes obscured by the lungs. ${ }^{6,7}$ The content and shape as well as the motility of the reticulum do not change during suckling. Likewise, the ultrasonographic appearance of the reticulum does not change during and after eating hay and grass silage but the frequency of contractions and the interval between contractions changes significantly. ${ }^{6,8}$ During feeding, the mean number of eontractions-of 10 calves during a 9-min measuring period was 18.5 , which was a significant increase from 11.1 before and 11.5 after feeding. Because of the increased rate of contractions, the interval between contractions was significantly shorter $(\mathrm{P}<0.01)$ during eating $(21.7 \mathrm{sec})$ than before $(41.1 \mathrm{sec})$ and after eating $(37.3 \mathrm{sec})$. The reticular contraction rate of $1.2 \pm 0.23$ per min in calves before feeding was very similar to the rate in resting cows of $1.2 \pm 0.13$ per $\min ^{12}$ but slightly higher than the rate of $0.9 \pm 0.19$ per min in pre-weaned calves. ${ }^{6,7}$ During feeding, the increase in the frequency of reticular contractions was greater in ruminating calves than in cows; in the former it almost doubled from 1.2 to 2.1 contractions per min and in the latter it increased from 1.2 to 1.6 contractions per min. ${ }^{12}$ The mean duration of the first and second contraction was 2.5 and $3.9 \mathrm{sec}$ in calves, which were similar to the values of 2.8 and $4.2 \mathrm{sec}$ measured in resting cows ${ }^{12}$ and 2.4 and $4.9 \mathrm{sec}$ in pre-weaned calves. ${ }^{6,7}$ Ruminating calves, pre-weaned calves and cows differed with respect to the speed 
of the first reticular contraction; it was $7.0 \mathrm{~cm} / \mathrm{sec}$ in cows,${ }^{8} 3.5 \mathrm{~cm} / \mathrm{sec}$ in ruminating calves and $1.7 \mathrm{~cm} / \mathrm{sec}$ in pre-weaned calves. ${ }^{6,7}$ The approximately 4 -fold increase from pre-weaned to ruminating calves to mature cows is an impressive illustration of the gradual reticular development in growing cattle.

\section{Rumen}

Examination of the rumen

The rumen is examined at the 6th to 12th intercostal spaces (ICSs) and the flank on both sides. ${ }^{11}$ Each ICS and the flank are scanned from dorsal to ventral with the transducer held parallel to the ribs. The size of the rumen is determined by defining the dorsal and ventral visible margins of the rumen by measuring the distance from each margin to the dorsal midline using a tape measure. The size is then calculated by subtracting the distance of the dorsal margin from the distance of the ventral margin. The location of the longitudinal groove is identified to determine the size of the rumen sacs. The dorsal rumen sac extends from the dorsal visible margin to the longitudinal groove and the ventral sac extends from the longitudinal sac to the ventral visible margin of the rumen. The thickness of the ruminal wall is best measured using a $13-\mathrm{MHz}$ transducer.

\section{Ultrasonographic findings of the rumen}

The rumen can be visualized from the first day of life. ${ }^{11}$ It is adjacent to the abdominal wall in the caudal abdomen and further cranially the spleen is seen between the abdominal wall and the rumen. The wall of the rumen is visible as an echoic line, and three layers including the serosal, muscular and mucosal tunics can be clearly differentiated using the $13-\mathrm{MHz}$ transducer. On the first day of life, the rumen content is anechoic with hyperechoic stippling and a small dorsal gas cap almost always can be seen. After the first day, most calves have reverberation artifacts dorsally (Fig. 2), indicating a gas cap, and an ingesta phase ventrally. The transition between the two phases is characterized by the abrupt disappearance of the reverberation artifact. Because of their gaseous nature, the ingesta and the ventral fluid phase cannot be seen. The ultrasonographic appearance of the rumen does not change in pre-weaned calves during and after the ingestion of milk $^{7}$ and in ruminating calves during and after eating hay and grass silage. ${ }^{8}$

The rumen is visible only from the left side on day 1 but from both sides thereafter. The longitudinal groove appears on the left as a mucosal fold, separating the dorsal and ventral sacs of the rumen, but the actual groove develops later (Fig. 3). Because of superimposition of 
the lung and spleen, the distance between the dorsal visible margin of the rumen and the dorsal midline is largest in the 7th ICS (Fig. 4). It becomes smaller further caudally and is smallest in the 12th ICS. In the flank, the distance between the dorsal midline and the dorsal margin of the rumen increases. In contrast, the distance between the dorsal midline and the ventral visible margin of the rumen does not change much.

In each ICS, the overall size of the rumen increases progressively with age (Fig. 5). The most pronounced increase occurs after weaning, which was between days 60 and 80 in a study at our clinic. The same is true for the size of the dorsal and ventral sacs of the rumen. Until day 40 , the dorsal and ventral sacs are similar in size, and after day 60 , the ventral sac is slightly larger. The length of the rumen also increases gradually; on the first day, the rumen does not extend beyond the last rib but can be seen in the flank region from day 20. The cranial dorsal blind sac of the rumen cannot be seen in the newborn but it appears as a semicircular structure between the reticulum and the ventral sac of the rumen from day 20 , similar to descriptions in adult cattle. It contracts immediately after the biphasic reticular contraction.

\section{Omasum}

\section{Examination of the omasum}

The omasum is examined on the right side from all ICSs from dorsal to ventral with the transducer held parallel to the ribs. ${ }^{7,11}$ The dorsal and ventral visible margins and the size of the omasum are determined analogous to the method used for the rumen.

\section{Ultrasonographic findings of the omasum}

The omasum can always be seen from the right side. ${ }^{11}$ It is medial to the liver dorsally and usually medial to the small intestines ventrally, and only occasionally directly adjacent to the abdominal wall. In the first few days of life, the omasum can occasionally also be seen from the 7th to 10th ICSs on the left side. It is seen on the right side from the 6th to 9th ICSs and occasionally from the 10th ICS. The best images are obtained at the 8th or 9th ICSs. In the newborn calf, the omasal wall usually appears as a completely circular line (Fig. 6). The omasal contents are echoic in these cases and the omasal leaves are seen as fine echoic lines. After a few days, the omasal contents can no longer be seen because of their gaseous nature, as described in adult cattle. The omasal wall then appears as a semi-circular to circular echoic line (Fig. 7). Sometimes the origin of the omasal leaves can be seen as echoic projections protruding into the omasal lumen. The ultrasonographic appearance of the omasum remains 
unchanged in suckling calves during the ingestion of milk ${ }^{7}$ and also in ruminating calves when they eat hay and grass silage. ${ }^{8}$

The dorsal visible border of the omasum has a caudodorsal course (Fig. 8). It is furthest from the dorsal midline at the 6th ICS and moves progressively closer to the dorsal midline toward the 10th ICS. The visible omasal size measured at the 8th and 9th ICSs increases in the first 100 days, whereas the size measured in the 6th and 7th ICSs does not change appreciably (Fig. 9). The visible omasal size is largest in the 8th ICS and smallest in the 6th ICS.

Typically, omasal motility cannot be detected.

\section{Abomasum \\ Examination of the abomasum}

The abomasum is scanned from the 5th to the 12th ICSs and the flank on both sides starting at the ventral midline and progressing laterally and dorsally with the transducer held parallel to the ribs. ${ }^{7,11}$ The location and size of the abomasum and visibility of its wall, folds and content are assessed before and after the ingestion of milk. The abomasal length is measured in the ventral midline. Video recordings can be made of the abomasum slightly to the left of the ventral midline during and after the ingestion of milk to document filling of the abomasum and clotting of the milk. The time between the start of milk intake and the appearance of the milk in the abomasum can be measured using a stop watch.

\section{Ultrasonographic findings of the abomasum}

The ultrasonographic appearance of the abomasum strongly depends on the time of milk intake. In the newborn calf, the abomasum is the largest organ and dominates the abdominal cavity. It is visible at the 5th to 12 th ICSs and from the ventral flank. The content is heterogeneous and hypoechoic with hyperechoic stippling (Fig. 10) and often contains hyperechoic particles of varying size reflecting clotted milk. The abomasal wall appears as a fine echoic line and the abomasal folds are often distinct. From day 80 onward, the pyloric part of the abomasum can often be seen on the right side parallel to the fundic part of the stomach. The pylorus usually is oval to circular in cross section and has a characteristic spoke wheel appearance. ${ }^{5}$

The influx of milk is readily seen and first appears as a cloud-like hyperechoic mass. This expands to fill the entire abomasal lumen and is seen as homogeneous hyperechoic content (Fig. 11). In contrast to cow's milk, milk replacer appears heterogeneous and hyperechoic. ${ }^{13}$ The mean interval between the start of nursing and the ultrasonographic appearance of milk in 
the abomasum varies from 10 to $25 \mathrm{sec}$ (range of individual examinations $5.9-68.0 \mathrm{sec}$ ). After the influx of milk, the abomasal content usually appears as homogeneous, and rarely heterogeneous, hyperechoic material, and the abomasal folds are seen as distinct, undulating, echoic folds. Toward the end of nursing, the first signs of milk clotting can usually be seen in the form of consolidation of the hyperechoic material. The homogeneous echoic content changes and forms a hypoechoic peripheral zone with hyperechoic stippling and echoic milk coagula. The abomasal milk content first forms a large homogeneous clump and distinct moving echoic stippling is seen in the peripheral fluid zone. A dorsal gas cap is sometimes seen after nursing as evidenced by reverberation artifacts on ultrasonograms. Distinct changes in the abomasal content are seen 15 min after milk intake (Fig. 12). The content becomes heterogeneous and the abomasal folds usually can no longer be seen. The clotted milk appears as hyperechoic clumps $s^{6,7,14,15}$ surrounded by a small rim of hypoechoic fluid. The clots usually measure more than $5 \mathrm{~cm}$ in diameter. Thirty minutes after milk intake, the abomasal folds are once again distinct. The visible clots are still the same size but they start to disintegrate and to become less distinct and overall less echoic, and the peripheral fluid rim becomes larger. By two hours after milk intake, the clumps are much smaller and their size varies from 1 to $5 \mathrm{~cm}$. The amounts of solid and liquid contents are about the same. The pylorus is much more difficult to identify after feeding than before but is always located in the right hemiabdomen. Of 29 calves fed milk replacer, eight had no ultrasonographic signs of curd formation 2 hours later. $^{16}$

On the first day of life, the abomasum is visible on both sides of the ventral midline but it extends more to the left than to the right. ${ }_{2}^{13}{ }^{11}$ Extension to the left varied from 8.9 to $15.1 \mathrm{~cm}$ and to the right from 3.1 to $17.1 \mathrm{~cm}$ before feeding (Fig. 13). After feeding, extension to the left and right varied from 8.9 to $23.2 \mathrm{~cm}$ and from 3.4 to $19.8 \mathrm{~cm}$, respectively. Similar measurements were made on days 20 to 60 and the visible extension of the abomasum to the left was greater than that to the right (Fig. 14). From day 80 (the calves were weaned at day $\underline{60}$ ),-abomasal extension to the left was smaller because of the expanding rumen. The visible extension to the right changed little in the first 100 days.

The mean visible abomasal length varied from 12.9 to $23.8 \mathrm{~cm}$ before feeding (Fig. 15) and changed little in the first 60 days. On day 100, the abomasal length was significantly greater $(\mathrm{P}<0.05)$ than on day 1 . With the exception of day 20 , the visible abomasal length was greater before feeding than after feeding $(\mathrm{P}<0.05)$.

Ultrasonographic measurements of abomasal dimensions (-width, length and height), location and emptying rate were made in suckling calves before and after they were fed different

Formatiert: Schriftart: Fett, Schriftfarbe: Hellblau, Durchgestrichen

Kommentiert [UW2]: Maybe indicate the age the animals were weaned if weaned during the study before $100 \mathrm{~d}$.

Formatiert: Schriftart: Fett, Schriftfarbe: Rot 
volumes of milk replacer or oral electrolyte solutions. ${ }^{14}$ All three abomasal dimensions increased during feeding, and after suckling, the abomasum was symmetrically located about the ventral midline. There were strong linear relationships between ultrasonographic and ingested volumes.

In contrast to feeding milk, the ultrasonographic appearance of the abomasum was the same before, during and after feeding hay and grass silage. ${ }^{8}$

Ultrasonography was used to examine the effect of erythromycin, neostigmine and metoclopramide on abomasal motility and emptying rate in suckling calves. ${ }^{17}$ Six Holstein calves were examined $1 \mathrm{~h}$ before until $3 \mathrm{~h}$ after being fed milk replacer $(60 \mathrm{ml} / \mathrm{kg})$. The calves received six treatments of varying doses of the three drugs given 30 min before feeding. A high dose of erythromycin $(8.8 \mathrm{mg} / \mathrm{kg})$ increased the frequency of abomasal luminal pressure waves and the mean abomasal luminal pressure and decreased the half-time of abomasal emptying by $37 \%$.

\section{Esophageal groove reflex and factors affecting groove closure}

Ultrasonographic monitoring of the esophageal groove reflex

The term esophageal groove reflex refers to the reflex spiral contraction of two muscular folds forming the lips of the groove and simultaneous relaxation of the reticulo-omasal orifice and the omasal canal creating a bypass from the esophagus to the abomasum. ${ }^{18}$ As a result, the ingested milk bypasses the reticulorumen and flows directly into the abomasum. The functioning of the esophageal groove reflex is easily monitored during suckling using ultrasonography; a functional reflex is confirmed when milk is seen entering the abomasum during milk intake. ${ }^{7,14,19}$ Complete or partial failure of the reflex can result from unnatural housing and feeding management ${ }^{18}$ or from neonatal disorders such as diarrhea. Milk given to a calf by tube feeding is deposited into the reticulorumen. ${ }^{20,21}$ When a healthy calf nurses, about $10 \%$ of the ingested milk reaches the reticulorumen ${ }^{22}$ from where it is actively transported through the omasum into the abomasum within three hours without adversely affecting the forestomach system..$^{23}$ Milk remaining in the rumen for an extended period of time undergoes bacterial lactose fermentation leading to a disorder referred to as ruminal drinker syndrome. ${ }^{24}$ Fermenting milk in the rumen of these calves can be detected ultrasonographically. ${ }^{6,25}$

\section{Examination of the esophageal groove reflex}

Conditions required for a functional esophageal groove reflex include a normal health status, spontaneous suckling, normal odor and taste of the milk and contact of the milk with relevant 
chemoreceptors in the oral cavity and esophagus. ${ }^{24}$ Visual, auditory and olfactory stimuli are also believed to be involved in esophageal groove closure. ${ }^{26}$ The effect of the feeding method and other factors on esophageal groove closure were recently investigated in healthy calves. ${ }^{13,19}$ The reflex was examined in milk-fed calves in the first 17 weeks of life. Other experiments were conducted to test the effect of various milk temperatures $(20,30,39,45$ $\left.{ }^{\circ} \mathrm{C}\right)$, different milk replacer concentrations (100, 125, $150 \mathrm{~g} / \mathrm{L}$ water), different feeding techniques (bucket feeding, different nipple positions) and different nipple openings (1 and 8 $\mathrm{mm}$ ) on esophageal groove closure. The reticulum and abomasum were monitored ultrasonographically before, during and after ingestion of milk using a 5-MHz convex transducer. The esophageal groove reflex was considered functional when milk was observed entering the abomasum during suckling. Esophageal groove closure occurred in all calves at each feeding in the first 17 weeks of life and in all calves at all examinations with all feeding techniques, at all milk temperatures and with all milk replacer concentrations. It should not be concluded from these findings that feeding technique has no effect on esophageal groove closure. More likely, occasional deviation from the optimal feeding technique, for instance the feeding of cold milk, does not adversely affect esophageal groove closure but can lead to digestive disorders if the suboptimal feeding management persists.

\section{Ruminal drinker syndrome}

Ultrasonographic examination of the reticulum is well suited for the differentiation of healthy calves and calves with ruminal drinker syndrome and to visualize the milk in the reticulorumen of the latter. In ruminal drinkers, the reticular wall appears as an echoic line ${ }^{25}$ as described in healthy calves ${ }^{7}$ but the two groups of calves differ with respect to the reticular content. Reticular content is not seen in healthy suckling calves ${ }^{7}$ but appears as hyperechoic and heterogeneous material in ruminal drinkers (Fig. 16). Reticular folds are distinct in ruminal drinkers ${ }^{25}$ and the honeycomb structure of the mucosa is often clearly visible (Fig. 17). Reticular contractions are biphasic as seen in healthy calves and the parameters of reticular contractions are similar ${ }^{25}$ to those seen in healthy suckling calves. ${ }^{7}$ Of note, reticular motility does not appear to be affected by the acidic and liquid content, although generally acidic rumen content has an adverse effect on forestomach motility in calves. ${ }^{27,28}$ Ultrasonography is very useful for the detection of milk in the ventral sac of the rumen in ruminal drinkers. The level of milky fluid may reach the longitudinal groove or in exceptional cases into the dorsal sac of the rumen, and the fluid is hypoechoic and heterogeneous. The ruminal wall measures on average $3.5 \mathrm{~mm}$ near the longitudinal groove and $3.2 \mathrm{~mm}$ in the 
ventral sac, compared with 2.2 and $1.7 \mathrm{~mm}$, respectively, in healthy calves. ${ }^{6,7,25}$ Ruminal drinkers and healthy calves do not differ in wall thickness of the dorsal sac of the rumen. The thickening of the ruminal wall in the lower ruminal region is a sequel of hyperkeratosis/parakeratosis and rumenitis, caused by increased butyric and lactic acid concentrations and characterized by epithelial loss, erosions and necrosis of the ruminal mucosa. ${ }^{24}$

Of ten calves with ruminal drinker syndrome, the ultrasonographic appearance of the rumen only changed in five during ingestion of milk; ${ }^{25}$ the milk entering the rumen was seen as hyperechoic fluid mixing with the fluid already present.

The ultrasonographic findings of the omasum and abomasum were similar in ruminal drinkers and healthy suckling calves. ${ }^{6,7,25}$ The omasal leaves were seen only occasionally in ruminal drinkers and the presence of a small amount of echoic fluid was the exception. The milk was seen entering the abomasum during suckling in all calves with ruminal drinker syndrome. As described for healthy suckling calves, ${ }^{5,14,15}$ the abomasal content of ruminal drinkers undergoes successive changes associated with coagulation of the milk.

\section{Liver}

Ultrasonography of the liver is of importance particularly in connection with the diagnosis of umbilical disorders. ${ }^{29-32}$ For instance, the enlarged umbilical vein can be followed into the liver in calves with omphalophlebitis, and liver abscesses are readily detected. ${ }^{29,31,32}$ Portosystemic shunt is very rare in cattle but the shunt between the cranial mesenteric vein and the caudal vena cava could be directly visualized in an affected calf. ${ }^{33}$

\section{Ultrasonographic examination of the liver}

The liver of calves is scanned on the right side from the 5th ICS to the cranial flank from dorsal to ventral with the transducer held parallel to the ribs ${ }^{9,10}$ as described for adult cattle, ${ }^{34}$ sheep ${ }^{35}$ and goats. ${ }^{36}$ The liver parenchyma is first assessed subjectively by determining its echogenicity and the parenchymal pattern and whether the hepatic blood vessels can be visualized, and the appearance of the liver surface is assessed. The dorsal and ventral liver margins are identified in each intercostal space and the size of the liver is calculated as described for adult cattle. ${ }^{34}$ The thickness of the liver is measured in each intercostal space at the level of the portal vein using the electronic cursors on frozen images. The shape, position and diameter of the caudal vena cava and portal vein, and the shape, size and content and appearance of the wall of the gallbladder are determined. 


\section{Ultrasonographic findings of the liver and gallbladder}

The parenchymal pattern of the liver consists of numerous fine echoes homogeneously distributed over the entire area of the organ (Fig. 18). ${ }^{9,10}$ Branches of the portal vein and the hepatic veins in the parenchyma increase in size toward the portal vein and caudal vena cava, respectively. The wall of the portal vein is generally better defined than that of the hepatic veins because of an echoic rim, but clear differentiation is only possible in the area where stellar ramifications of the portal vein branch into the parenchyma. The intrahepatic bile ducts usually cannot be seen. The liver is always seen at the 5th to 12th ICSs and behind the last rib in healthy calves. Cranially it is adjacent to the diaphragm and dorsally there is superimposition of the lungs as far back as the 11th or 12th ICS. The dorsal visible margin of the liver runs parallel to the ventral border of the lungs from cranioventral to caudodorsal (Fig. 19). The distance of the dorsal visible margin of the liver from the dorsal midline decreases caudally because the liver becomes less obscured by the lung. The distance between the dorsal visible margin of the liver and the dorsal midline was greatest at the 5th ICS and shortest at the 11th ICS. The ventral visible margin had a similar course; it was furthest from the dorsal midline at the 5th ICS and closest to the dorsal midline at the cranial flank. The visible size of the liver is largest at the 8th to 11th ICSs and is considerably smaller cranially and caudally (Fig. 20). There is no measurable increase in liver size in the first 60 days, and the size is smaller at 80 and 100 days than in the first 60 days. The thickness of the liver increases until day 40 and changes little thereafter until day 100 (Fig. 21). The maximum thickness is measured at the 8th and 9th ICSs.

The caudal vena cava is triangular in cross section attributable to its location in the sulcus of the vena cava of the liver (Fig. 18) (10 $^{10}$ but occasionally is round to oval. The vein is always seen in at least one ICS, most commonly at the 9th to 12th ICSs, but is not seen cranial to these ICSs because of superimposition of the lungs. The mean circumference of the vein of newborn calves is largest at the 10th and 11th ICSs and varies from 3.8 to $4.3 \mathrm{~cm}$. The circumference increases slightly and is largest at $6.5 \mathrm{~cm}$ at 40 days.

The portal vein is circular or oval in cross section and has stellate ramifications branching into the liver parenchyma (Fig. 22). ${ }^{9,10}$ The wall is more echogenic than the wall of the caudal vena cava, and the portal vein is seen at more ICSs than the caudal vena cava because of a more ventral position and less superimposition of the lungs. It is always seen at the 7 th to 11 th ICSs. Compared with the caudal vena cava, the portal vein is always more ventral and closer to the diaphragmatic surface of the liver. The diameter of the vein varies little in the first 100 
days (Fig. 23) and is smaller at the cranial ICSs than at the caudal ICSs. It ranges from 1.2 to $1.8 \mathrm{~cm}$ at the 9 th to 11 th ICSs.

The gallbladder is circular, oval or pear-shaped (Fig. 24) $)^{9,10}$ and sometimes extends beyond the ventral margin of the liver depending on the amount of bile. The content is anechoic and the wall is hyperechoic. The gallbladder can almost always be visualized, most commonly at the 9th ICS. It is often seen at more than one ICS and rarely at only one or at three. The mean length varies from 1.5 to $5.5 \mathrm{~cm}$ and the mean width from 0.9 to $1.8 \mathrm{~cm}$.

\section{Abnormal ultrasonographic findings of the liver and gallbladder}

Ultrasonographic changes of the liver in connection with umbilical disorders were recently described in detail. ${ }^{32}$

\section{Umbilicus}

The ultrasonographic examination of the umbilicus and ultrasonographic findings in calves with umbilical disorders were recently described. ${ }^{32}$

\section{Conclusions}

This article forms a guideline for the ultrasonographic examination of the abdomen in calves. Abdominal ultrasonography is primarily indicated for the assessment of the gastrointestinal tract of diseased calves but is also useful in experimental settings. Ultrasonography allows for non-invasive abdominal assessment and enhances animal welfare via the reduction of painful diagnostic procedures.

\section{References}

1. Braun U. Ultrasonography of the gastrointestinal tract in cattle. Vet Clin North Am Food Anim Pract 2009; 25(3):567-90.

2. Braun U, Schnetzler C, Ohlerth S, Hatz L, Augsburger H. Computed tomography of the abdomen of calves during the first 105 days of life: I. Reticulum, rumen, omasum and abomasum. Schweiz Arch Tierheilk 2014; 156(5): 217-25.

3. Braun U, Schnetzler C, Augsburger H, Müller U, Dicht S, Ohlerth S. Computed tomography of the abdomen of calves during the first 105 days of life: II. Liver, spleen, and small and large intestines. Schweiz Arch Tierheilk 2014; 156(5): 227-36. 
4. Braun U, Schnetzler C, Augsburger H, Bettschart R, Ohlerth S. Computed tomography of the abdomen of calves during the first 105 days of life: III. Urinary tract and adrenal glands. Schweiz Arch Tierheilk 2014; 156(5): 237-47.

5. Jung C. Sonographie der Lunge und des Abdomens beim bovinen Neonaten unter besonderer Berücksichtigung pathologischer Veränderungen [Dissertation]. Giessen, Fachbereich 10 - Veterinärmedizin, Justus-Liebig-University of Giessen; 2002.

6. Gautschi A. Sonographische Untersuchungen an Haube, Pansen, Psalter und Labmagen von 30 Kälbern [Dissertation]. Zurich, Vetsuisse Faculty, University of Zurich; 2010.

7. Braun U, Gautschi A. Ultrasonography of the reticulum, rumen, omasum and abomasum in 10 calves before, during and after ingestion of milk. Schweiz Arch Tierheilk 2012; 154(7):287-97.

8. Braun U, Gautschi A, Tschuor A, Hässig M. Ultrasonography of the reticulum, rumen, omasum and abomasum before, during and after ingestion of hay and grass silage in 10 calves. Res Vet Sci 2012; 93(3):1407-12.

9. Krüger SS. Sonographische Untersuchungen an Haube, Pansen, Psalter, Labmagen, Milz und Leber von Kälbern von der Geburt bis zum Alter von 100 Tagen [Dissertation]. Zurich, Vetsuisse Faculty, University of Zurich; 2012.

10. Braun U, Krüger S. Ultrasonography of the spleen, liver, gallbladder, caudal vena cava and portal vein in healthy calves from birth to 104 days of age. Acta Vet Scand 2013; 55: 68.

11. Braun U, Krüger S, Hässig M. Ultrasonographic examination of the reticulum, rumen, omasum and abomasum during the first 100 days of life in calves. Res Vet Sci (2013); 95 (2):326-33.

12. Braun U, Rauch S. Ultrasonographic evaluation of reticular motility during rest, eating, rumination and stress in 30 healthy cows. Vet Rec 2008; 163(19): 571-4.

13. Brammertz C. Überprüfung der Schlundrinnenfunktion bei Kälbern, Rinder und Kühen mittels sonographischer Untersuchung [Dissertation]. Zurich, Vetsuisse Faculty, University of Zurich, 2014.

14. Wittek T, Constable PD, Marshall T, Crochik S. Ultrasonographic measurement of abomasal volume, location, and emptying rate in calves. Am J Vet Res 2005, 66(3): 53744.

15. Miyazaki T, Miyazaki M, Yasuda J, Okada K. Ultrasonographic imaging of abomasal curd in preruminant calves. Vet J 2009; 179(1): 109-16. 
16. Miyazaki T, Miyazaki M, Yasuda J, Okada K. No abomasal curd formation in preruminant calves after ingestion of a clotting milk replacer. Vet J 2010; 183(2): 205-9.

17. Wittek T, Constable PD. Assessment of the effects of erythromycin, neostigmine, and metoclopramide on abomasal motility and emptying rate in calves. Am J Vet Res 2005; 66(3): 545-52.

18. Kaske M. Motorik des Magen-Darm-Kanals. In: Engelhardt W, Breves G, editors. Physiologie der Haustiere. Stuttgart: Enke Verlag; 2010. p 347-79.

19. Braun U, Brammertz C. Ultrasonographic examination of the oesophageal groove reflex in young calves under various feeding conditions. Schweiz Arch Tierheilk 2015; 157 (8): 457-63.

20. Schipper IA, Colville T, Samuel CW, Misek A. The effects of intubation feeding of the newborn calf. Farm Res 1984; 42(2): 14-7.

21. Dirksen G, Baur T. Pansenazidose beim Milchkalb infolge Zwangsfütterung. Tierärztl Umschau 1991; 46(1): 257-61.

22. Ruckebusch V, Kay RNB. Sur le réflexe de fermeture de la gouttière oesophagienne. Ann Biol Anim Biochim Biophys 1971;11(2): 281.

23. Lateur-Rowet HJM, Breukink HJ. The failure of the oesophageal groove reflex, when fluids are given with an oesophageal feeder to newborn and young calves. Vet Quart 1983; 5(2): 68-74.

24. Dirksen G. Krankheiten von Haube und Pansen bei Milchkalb und Jungrind. In: Dirksen G, Gründer HD, Stöber M, editors. Innere Medizin und Chirurgie des Rindes. Berlin: Parey Buchverlag; 2002. p 455-69.

25. Braun U, Gautschi A. Ultrasonographic examination of the forestomachs and the abomasum in ruminal drinker calves. Acta Vet Scand 2013; 55: 1.

26. Abe M, Iriki T, Kondoh K, Shibui H. Effects of nipple or bucket feeding of milksubstitute on rumen by-pass and on rate of passage in calves. Br J Nutr 1979; 41(1):17581.

27. Breukink HJ, Wensing T, Van Weeren-Keverling Buisman A, Van BruinessenKapsenberg EG, De Visser NA. Consequences of failure of the reticular groove reflex in veal calves fed milk replacer. Vet Quart 1988; 10(2): 126-35.

28. Bättig U, Regi G, Stocker H. Pansensaft-Untersuchung bei Kälbern mit gestörter und normaler Sauglust. Tierärztl Prax 1992; 22(1):44-8. 
29. Lischer CJ, Steiner A. Ultrasonography of the umbilicus in calves. Part 2: Ultrasonography, diagnosis and treatment of umbilical diseases. Schweiz Arch Tierheilk 1994; 136(6-7): 227-41.

30. Heidemann A, Grunert E. Ultraschalldiagnostik als Entscheidungshilfe für das weitere Vorgehen bei Nabelentzündungen des neugeborenen Kalbes. Prakt Tierarzt 1995; 76(9): 742-6.

31. Flöck M. Ultraschalldiagnostik von Entzündungen der Nabelstrukturen, persistierendem Urachus und Umbilikalhernie beim Kalb. Berl Münch Tierärztl Wschr 2003; 116(1-2): 211.

32. Steiner A, Lejeune B. Ultrasonographic assessment of umbilical disorders. Vet Clin North Am Food Anim Pract 2009; 25(3): 781-93.

33. Buczinski S, Duval J, D'Anjou MA, Francoz D, Fecteau G. Portocaval shunt in a calf: Clinical, pathologic, and ultrasonographic findings. Can Vet J 2007; 48(4): 407-10.

34. Braun U, Gerber D. Influence of age, breed, and stage of pregnancy on hepatic ultrasonographic findings in cows. Am J Vet Res 1994;55(9):1201-5.

35. Braun U, Hausammann K. Ultrasonographic examination of the liver in sheep. Am J Vet Res 1992; 53(2):198-202.

36. Braun U, Steininger K. Ultrasonographic characterization of the liver, caudal vena cava, portal vein, and gallbladder in goats. Am J Vet Res 2011; 72(2):219-25 


\section{Legend to Figures}

Fig. 1. Ultrasonogram of the reticulum in a 44-day-old Holstein-Friesian calf imaged from the left paramedial sternal region using a 5-MHz convex transducer. 1 Ventral abdominal wall, 2 Reticulum, 3 Abomasum, 4 Spleen, Cr Cranial, Cd Caudal. Reproduced from Braun et al. ${ }^{11}$

Fig. 2. Ultrasonogram of the dorsal sac of the rumen in a 3-month-old Brown Swiss calf viewed from the 11th intercostal space on the left side in the region of the dorsal gas cap using a 5.0-MHz linear transducer. 1 Lateral abdominal wall, 2 Rumen wall, 3 Reverberation artifact at the level of the dorsal gas cap in the rumen, Ds Dorsal, Vt Ventral. Reproduced from Braun et al. ${ }^{11}$

Fig. 3. Ultrasonogram of the rumen in a 44-day-old Holstein-Friesian calf imaged from the 11th intercostal space on the left side using a 5-MHz convex transducer. 1 Lateral abdominal wall, 2 Wall of the dorsal sac of rumen, 3 Longitudinal groove, 4 Wall of the ventral sac of rumen, Ds Dorsal, Vt Ventral. Reproduced from Braun et al. ${ }^{11}$

Fig. 4. Dorsal and ventral visible margins of the rumen imaged from the 7th intercostal space to the caudal flank on the left side in six 62-day-old Holstein-Friesian calves (examination 4, (-mean \pm standard deviation). Reproduced from Braun et al. ${ }^{|1|}$

Fig. 5. Size of the dorsal and ventral ruminal sacs and the entire rumen imaged from the left side at the 11th intercostal space in six Holstein-Friesian calves during the first 104 days of age (mean \pm standard deviation). Examination numbers 1, 2, 3, 4, 5, and 6 correspond to the ages of 2, 20, 41, 62, 83, and 99 days. Reproduced from Braun et al. ${ }^{11}$

Fig. 6. Ultrasonogram of the omasum imaged from the 8th intercostal space in a one-day-old Holstein-Friesian calf. The omasum is circular and the omasal leaves are visible as distinct echoic lines. 1 Lateral abdominal wall, 2 Liver, 3 Omasum, Ds Dorsal, Vt Ventral. Reproduced from Krüger ${ }^{9}$

Fig. 7. Ultrasonogram of the omasum imaged from the 7th intercostal space in a 104-day-old Holstein-Friesian calf. The omasum is medial to the liver and its wall is seen as an echoic convex line. The omasal leaves and the omasal content are not visible because of the gaseous nature of the latter. Reproduced from Krüger ${ }^{9}$
Kommentiert [UW4]: Concerning the reprint we need to have a permission for reproducing it. I will let the editorial office in charge of that.

Kommentiert [UW5]: It is not clear what the number of examination is. If I understand correctly this ist the examination day. Maybe define number of examination or replace it by examination number or days of examination. (same for other similar pictures)

Formatiert: Schriftfarbe: Rot, Durchgestrichen 
Fig. 8. Dorsal and ventral visible margins of the omasum imaged from the right side at the 6th to the 10th intercostal spaces in six 40-day-old Holstein-Friesian calves (mean \pm standard deviation). For key for the examination numbers see Fig. 5. Reproduced from Braun et al. ${ }^{11}$

Fig. 9. Visible size of the omasum imaged from the right side at the 6th to the 9th intercostal spaces in six Holstein-Friesian calves from birth to 104 days of age (mean \pm standard deviation). Reproduced from Braun et al. ${ }^{11}$

Fig. 10. Ultrasonogram of the abomasum of a Holstein-Friesian calf before suckling. A 5.0MHz linear transducer was used to scan the ventral abdomen. The ingesta appear heterogeneous and have echoic and hypoechoic components. 1 Ventral abdominal wall, 2 Abomasal wall, 3 Abomasal contents, Cr Cranial, Cd Caudal. Reproduced from Braun and Gautschi $^{7}$

Fig. 11. Ultrasonogram of the abomasum of a Holstein-Friesian calf during suckling. A 5.0$\mathrm{MHz}$ linear transducer was used to scan the ventral abdomen. The ingested milk has not clotted yet and appears as a homogeneous mass. The abomasal folds are clearly visible. 1 Ventral abdominal wall, 2 Milk that has just entered the abomasum, 3 Abomasal folds, $\mathrm{Cr}$ Cranial, Cd Caudal. Reproduced from Braun and Gautschi ${ }^{7}$

Fig. 12. Ultrasonogram of the abomasum of a Holstein-Friesian calf 30 min after suckling, viewed from ventral using a 5.0-MHz linear transducer. The abomasal contents are heterogeneous and the clotted milk is seen as echoic clumps. Hypoechoic fluid is visible at the periphery of the abomasal lumen. 1 Ventral abdominal wall, 2 Abomasal wall, 3 Rim of hypoechoic fluid, 4 Clotted milk, Cr Cranial, Cd Caudal. Reproduced from Braun and Gautschi $^{7}$

Fig. 13. Laterolateral extension of the abomasum before and after ingestion of milk imaged from the ventral abdominal wall from the 5 th intercostal space to the flank (means) in six newborn Holstein-Friesian calves. Reproduced from Braun et al. ${ }^{11}$

Fig. 14. Laterolateral extension of the abomasum before and after suckling imaged from the ventral abdominal wall at the level of the 10th intercostal space in six Holstein-Friesian calves 
during the first 104 days of age (mean \pm standard deviation). *, ** Difference between left and right $(\mathrm{P}<0.05$ and $<0.01$, respectively $), \uparrow$ Differences between examinations $4 / 5$ and $4 / 6$ $(\mathrm{P}<0.05)$. For key for the examination numbers see Fig. 5. Reproduced from Braun et al. ${ }^{11}$

Fig. 15. Length of the abomasum imaged from the ventral midline before and after suckling in six Holstein-Friesian calves during the first 104 days of age (mean \pm standard deviation). There are no post-suckling measurements at examinations 5 and 6 because the calves had been weaned. * Difference between before and after feeding $\left(\mathrm{P}<0.05\right.$; paired t-test). ${ }^{\text {a }}$ Difference between examinations 1 and 6 ( $\mathrm{P}<0.05$; paired t-test). For key for the examination numbers see Fig. 5. Reproduced from Braun et al. ${ }^{11}$

Fig. 16. Ultrasonogram of the reticulum of a 37-day-old Swiss Braunvieh calf with ruminal drinking syndrome. The 5.0-MHz linear transducer was held parallel to the sternum in the left lower thoracic area. The reticular content appears heterogeneous and echoic and the honeycomb-like structure of the mucosa can be seen. 1 Abdominal wall, 2 Spleen, 3 Reticular wall, 4 Reticular content, 5 Honeycomb-like structure of the mucosa, Cr Cranial, Cd Caudal. Reproduced from Braun and Gautschi ${ }^{25}$

Fig. 17. Ultrasonogram of the ventral sac of the rumen of a 27-day-old Swiss Braunvieh calf with ruminal drinking syndrome. The 5.0-MHz linear transducer was held parallel to the ventral midline in the left lower abdominal area. The ruminal content appears heterogeneous and echoic. The undulating line medial to the ruminal wall indicates hyperkeratosis. 1 Ventral abdominal wall, 2 Ruminal wall, 3 Ruminal content, Cr Cranial, Cd Caudal. Reproduced from Braun and Gautschi ${ }^{25}$

Fig. 18. Ultrasonogram of the liver and caudal vena cava viewed from the 11th intercostal space on the right side in a 95-day-old Holstein-Friesian calf. 1 Abdominal wall, 2 Liver, 3 Caudal vena cava, 4 Rumen, Ds Dorsal, Vt Ventral. Reproduced from Braun and Krüger ${ }^{10}$

Fig. 19. Dorsal and ventral visible margins of the liver at the 5th to the 12 th intercostal spaces and the cranial flank on the right side in six Holstein-Friesian calves (41.0 \pm 0.76 days old, mean \pm standard deviation). Reproduced from Braun and Krüger ${ }^{10}$ 
Fig. 20. Size of the liver (distance between the dorsal margin of the liver and the dorsal midline subtracted from the distance between the ventral margin of the liver and the dorsal midline) at the 5th to 12 th intercostal spaces in six healthy Holstein-Friesian calves at examinations 1 to 6 (mean - standard deviation). ICS Intercostal space. For key for the examination numbers see Fig. 5. Reproduced from Braun and Krüger ${ }^{10}$

Fig. 21. Thickness of the liver at the 7th, 9th, and 11th intercostal spaces in six healthy Holstein-Friesian calves at examinations 1 to 6 (mean - standard deviation). ICS Intercostal space. For key for the examination numbers see Fig. 5. Reproduced from Braun and Krüger ${ }^{10}$

Fig. 22. Ultrasonogram of the portal vein viewed from the right side in an 83-day-old Holstein-Friesian calf. 1 Abdominal wall, 2 Liver parenchyma, 3 Portal vein, Ds Dorsal, Vt Ventral. Reproduced from Braun and Krüger ${ }^{10}$

Fig. 23. Diameter of the portal vein at the 7th, 9 th, and 11th intercostal spaces in six healthy Holstein-Friesian calves at examinations 1 to 6 (mean - standard deviation). ICS Intercostal space. For key for the examination numbers see Fig. 5. Reproduced from Braun and Krüger ${ }^{10}$

Fig. 24. Ultrasonogram of the gallbladder viewed from the right side in a 62-day-old HolsteinFriesian calf. 1 Abdominal wall, 2 Liver, 3 Gallbladder, Ds Dorsal, Vt Ventral. Reproduced from Braun and Krüger ${ }^{10}$ 